\title{
Tendencies and Characteristics of Financial Distress: An Introductory Comparative Study among Three Industries in Albania
}

\author{
By Zhaklina Dhamo* \\ Vasilika Kume
}

\begin{abstract}
Due to the presence fiscal evasion and the lack of publicly available financial statements, one of the least studied characteristics of the Albanian entrepreneurship activities during the last 25 years has been the bankruptcy potential. Considered as the leading business sector of the local economy, this research studies the financial distress characteristics of the energy, telecommunication, and construction sector in the Albanian economy. Due to the lack of financial market data, and bureaucratic loopholes in the Albanian legal framework, the methodology employed is in line with Altman (2000) for predicting financial distress. The probability of default of the Albanian corporations, considered in this paper, is assessed based on the $Z^{\prime}$ and $Z^{\prime \prime}$ methodology, according to which the driving factors to financial distress are liquidity, profitability, productivity, leverage, and the sales generating the ability of the assets of companies considered in this research. The insolvency tendencies and characteristics of the three industries are analyzed in this research. The source of data is the National Registration Center (NRC) of Albanian businesses, for Albanian "VIP" companies, as classified from the Albanian Tax Authority. None of the sectors in the study can be classified as default, based on the samples analyzed and the models employed. Telecommunication shows the lowest exposure to default in the most recent year. The liquidity and leverage of the sector decreases the probability of default. All ratios show a gradual decrease of the financial health for energy, while the construction sector ratios seem more volatile from year to year. The difficulty in identifying bankruptcy cases is one of the limitations of this study. A natural extension of this study might be the quantitative bankruptcy modeling of Albanian companies. Factor loadings of the explanatory variables may change from the original models of Altman $Z^{\prime}$ and $Z^{\prime \prime}$.
\end{abstract}

Keywords: Altman's Z, Financial Distress, Sector Efficiency.

\section{Introduction}

This research, to the best of our knowledge, has been the first attempt to study the financial characteristics, from a corporate bankruptcy perspective, of the construction, energy and telecommunication industry in Albania.

Beaver (1966) was one of the first authors to highlight the importance of the ratio analysis in terms of prediction of enterprise failure. The analysis, however, was univariate in nature. The compounding effect, through multidiscriminant analysis, was first introduced by Altman (1968). The author studied the cumulative effect of the linear combination of firm characteristics, through ratios, that best allocated companies in the two identified groups, the failed ones and non-failed ones. Altman, in his original study, found five ratio

\footnotetext{
* PhD Candidate, Tirana University, Albania.

${ }^{\dagger}$ Professor, Tirana University, Albania.
} 
characteristics that, if linearly combined, best predicted the bankruptcy potential of a manufacturing company operating in the US. The ratios are Working Capital/Total Assets, Retained Earnings/Total Assets, EBIT/Total Assets, Market Value of Equity/Book Value of Debt, Sales/Total Assets. The first $\mathrm{Z}$ model introduced by Altman predicted $94 \%$ of the bankruptcy cases correctly. Beaver (1966) and Altman (1968) defined the two types of errors, potentially occurring from these models as Type 1 error, qualifying a failed firm as non-failed, and Type 2 error, qualifying a non-failed firm as a failed one. According to the model suggested by Altman (1968), bankruptcy can be accurately predicted up to two years before failure.

Altman et al. (1977) suggested a revised model for predicting bankruptcy risk, with a $70 \%$ accuracy over a five year period, and applicable to retailing firms. Results proved to be suggestive also for the subsequent samples, as Altman and Heine (2000) present. The accuracy of the original Z-Score model ranged from $82 \%$ to $94 \%$, when applied to data after the first research (Altman, 1968). In this research, the author introduced two revised versions of the $Z$ model, $Z^{\prime}$ and $Z^{\prime \prime}$. In the first one, the author has taken into account privately held companies, by substituting the market value of equity with the book value of equity in the fourth ratio of the model. In the second revised version of the model, Altman considered not only privately held companies, but industry effect as well, by putting out of the model Sales/Total Assets, a ratio, as advocated by many, to be influenced by the industry the firm operates.

Altman (2005) introduced an emerging market model that may be applied to non-manufacturing companies and privately held entrepreneurships as well. A constant of 3.25, which represents the median score of US Bankrupt entities, was added to the $Z^{\prime \prime}$ model. Then, the rating is adjusted to account for the currency devaluation risk, industry, competitive position, special debt issue feature and comparison with sovereign debt.

Chava and Jarrow (2004) suggest an innovative approach, by using monthly intervals for improving the bankruptcy prediction. Smith and Liou (2007) introduced macro variables in predicting financial distress, which may contribute in the development of the sector models. Hayes et al. (2010) focused in the predictive power of the $Z^{\prime \prime}$ model in the retail sector in the US, resulting to a $94 \%$ accuracy in bankruptcy prediction.

Balkaen and Ooghe (2004) considered the use of only annual accounting data as not enough, since important information is not disclosed solely in the balance sheet and income statement. In a review of the literature regarding the bankruptcy prediction models, Anjum (2012) evidenced three alternative models to the univariate/MDA approaches, logit and probit analysis, recursive partitioning and algorithm, and neural networks. Altman et al. (2014) found, through its review research, that Z"-Score Model performs well internationally.

Muminovic (2013) found that tiny changes cannot improve the accuracy of the $\mathrm{Z}$ score models. Thus, the author suggests that local/specific market models are worthwhile investing for. Altman et al. (2013) evidenced that the use of the Z" model for Italian manufacturing companies is appropriate, with caution. Low capitalization, heavy use of bank credit and budget policies which at times 
are not transparent and the characteristics of studied companies, enhance the potential to reformulate the parameters of the model in the Italian contest.

Inspired by the seminal work of Altman and other authors, we studied the bankruptcy characteristics of the construction industry, telecommunications, and energy in Albania during the period 2011-2013. We used the modified versions of the original Z Score model proposed by Altman (1968), the $Z^{\prime}$ and $Z^{\prime \prime}$ model, because, as analyzed in the methodology section, seem to be the most appropriate models for the Albanian company characteristics. Furthermore, we attempted to investigate the motives, through a sector ratio analyses, which yields the level of creditworthiness for the three business sectors included in this study.

This paper follows with a brief description of the methodology. Section three describes the data and sources of the data used in the Z-Score sector assessment. The next section introduces the bankruptcy potential results of the construction of the telecommunication and energy sector, which is immediately followed with an analytical investigation of the potential reasons, which may be found in the companies' financials, of the level of performance yield, from the bankruptcy potential perspective. The last section summarizes the concluding remarks of this study.

\section{Methodology}

The original Z-Score model, proposed by Altman (1968), cannot be used in the Albanian case, since no company registered in Albania, to the best of our knowledge, is publicly traded. Considering the fact that the independent variable $\mathrm{X}_{4}$ (market value of equity/book value of total liabilities) in the original Z-Score model cannot be observed, the $\mathrm{Z}$ model is excluded from our study.

Altman (2005) and Muminovic (2013) suggest the use of a local firm's data to build a tailored-made bankruptcy model, which fits the characteristics of the country/region. However, this is very difficult to be achieved for the Albanian companies, due to the lack of data for bankruptcy filings. The main reason may be the lack of corporate culture, because, until the early nineties, all firms were state owned. As a consequence, the practice of solvency/bankruptcy has not been built, although the level of non-performing loans, as per the declaration of the Albanian Association of Banks, amounts to more than $20 \%$. The lack of enough bankruptcy filing cases makes it highly difficult to quantitatively assess the financial distress characteristics of Albanian companies, using approaches well documented in the previous studies, mentioned in the above section.

In such conditions, the use of proxy models applicable in developing countries, which use the financial information of privately held firms, seem to be the only choice in assessing the financial distress characteristics of the construction, energy and telecommunication industry in Albania. The use of Altman's (2005) EM Score, based on our qualitative analyses, seems to not be 
very feasible, because there is not enough information for rating adjustments through the assessment of the currency devaluation risk, industry, competitive position, special debt issue feature and comparison with sovereign debt, for the case of the Albanian companies.

Based on the rationale described above, we have choosen to use the Altman's (2000) $Z^{\prime}$ and $Z^{\prime \prime}$ models for the quantitative assessment of the distress position for the construction, telecommunication, and energy industry in Albania.

The formula of the $\mathrm{Z}^{\prime}$ model is:

$$
Z^{\prime}=0.717\left(X_{1}\right)+0.847\left(X_{2}\right)+3.107\left(X_{3}\right)+0.420\left(X_{4}\right)+0.998\left(X_{5}\right)
$$

where,

$\mathrm{X}_{1}=$ Working Capital/Total Assets (a measure of liquid assets relative to total capitalization.

$\mathrm{X}_{2}=$ Retained Earnings/Total Assets (a measure of relative cumulative profitability over time).

$\mathrm{X}_{3}=\mathrm{EBIT} / \mathrm{Total}$ Assets (a productivity measure of the firms' assets).

$\mathrm{X}_{4}=$ Book Value of Equity/Book Value of Total Debt (a measure of the relative tolerance regarding a decline in value of assets until the company becomes insolvent).

$\mathrm{X}_{5}=$ Sales/Total Assets (a measure of the sales generating the ability of company's assets).

$\mathrm{Z}^{\prime}=$ Overall index value.

If the $\mathrm{Z}^{\prime}$ score is lower than 1.23 , then the tested firm is indicated as bankrupt. If the score is higher than 2.9, than the tested firm, according to the model, is non-bankrupt. A score between 1.23 and 2.9, considered as gray area or zone of ignorance by the author, does not say much regarding the solvency position of the tested firm.

Another modified version of the model, which takes away the impact of the industry effect, according to the author, is $Z^{\prime \prime}$, as per the formula:

$$
Z^{n}=6.56\left(X_{1}\right)+3.26\left(X_{2}\right)+6.72\left(X_{3}\right)+1.05\left(X_{4}\right)
$$

Indeed, the coefficients of $X_{1}, X_{2}, X_{3}$ and $X_{4}$ have changed from $Z^{\prime}$ to $Z^{\prime \prime}$, since in the latter model is missing $X_{5}$ (Sales/Total Assets), a variable that is industry sensitive, according to the authors. If the score is lower than 1.1, the company is indicated as insolvent. If the score is higher than 2.65, the company is indicated as non-bankrupt. The gray area score, between 1.1 and 2.65, does not say much regarding the solvency potential of the firm.

We have choosen the five most representing companies of each sector, according to a rationale explained in next section. We applied the $Z^{\prime}$ and $Z^{\prime \prime}$ model to the companies' financials of year 2011-2013. We finded the mean, minimum and maximum scores for both models in each industry, for three 
consecutive years, as summarized in Table 1. Then, the analyses of each sector bankruptcy position through three years, with relative gray areas of each model, are summarized in Figures 1-3. The research also seeks financial reasons of specific performance scores of each industry, through analyzing the ratios used in both models for each sector, as summarized in Table 2. The next section presents the data used in this research work.

\section{Data}

We focus on the solvency position analysis of this research in three business sectors in Albania, construction, energy and telecommunication. Since no well-functioning financial market operates in Albania, the choice of companies in each sector cannot be done by studying the respective market capitalization. We use the list of VIP companies from the Albanian Tax Authority. The list considers the biggest entity tax payers operating in Albania. Five companies for each of the three sectors analyzed in this study are chosen from this list.

The financial statements of these companies are downloaded from the official website of the National Registration Center of the Republic of Albania $^{1}$. From the financial statements of the 15 companies included in this study, the drawn data are current assets, current liabilities, total assets, total liabilities, sales, EBIT, retained earnings and book value of equity, for the years 2011, 2012, 2013.

Next section presents a thorough analysis of the bankruptcy potential the construction, telecommunication, and energy sectors of Albania.

\section{Analysis of the Z Models Results}

Table 1 presents the key statistics for the $Z^{\prime}, Z^{\prime \prime}$ scores of the construction, energy and telecommunication industry operating in Albania.

The best $Z^{\prime}$ score seems to be achieved from the telecommunication industry in 2013, although the variability in score within the same industry is the highest. The telecommunication industry seem to have been improving from year to year in terms of solvency, according to the $Z^{\prime}$ test, although variability in score seem to have increased as well. The same insights are suggested by $Z^{\prime \prime}$ results.

Although with a lower variability than telecommunication, the energy sector seemed to be higher exposed to solvency problems, according to the $Z^{\prime}$ score. The situation becomes worse from year to year, with the increase of variability and increase of risk solvency as well. The $Z^{\prime \prime}$ approach suggests an even worse picture, with the energy sector that seemed to be more exposed to financial distress and compared with the construction sector, in the last two years of study.

\footnotetext{
${ }^{1}$ http://www.qkr.gov.al.
} 
In terms of the variability of exposure to distress, the construction sector showed mixed results from year to year. The $Z^{\prime}$ score shows the highest exposure to distress for this model. According to the $Z$ " results, although not the most exposed to bankruptcy among three sectors, the exposure of the construction sector has been increasing from year to year.

Table 1. Summary Statistics of the Z-Score among Three Models, for the Industries Included in this Study

\begin{tabular}{|c|c|c|c|}
\hline \multicolumn{4}{|c|}{2013} \\
\hline & & $Z^{\prime}$ & $\mathrm{Z}^{\prime \prime}$ \\
\hline \multirow[t]{3}{*}{ Telecommunication } & Mean & 2.628 & 5.619 \\
\hline & $\operatorname{Max}$ & 6.791 & 20.170 \\
\hline & Min & $(1.090)$ & $(5.316)$ \\
\hline \multirow[t]{3}{*}{ Energy } & Mean & 2.216 & 1.518 \\
\hline & Max & 4.314 & 6.459 \\
\hline & Min & $(2.003)$ & $(7.489)$ \\
\hline \multirow[t]{3}{*}{ Construction } & Mean & 1.839 & 3.008 \\
\hline & $\operatorname{Max}$ & 3.805 & 9.971 \\
\hline & Min & 0.664 & $(0.129)$ \\
\hline \multicolumn{4}{|c|}{2012} \\
\hline & & $Z^{\prime}$ & $\mathrm{Z}^{\prime \prime}$ \\
\hline \multirow[t]{3}{*}{ Telecommunication } & Mean & 2.309 & 4.749 \\
\hline & $\operatorname{Max}$ & 6.050 & 17.479 \\
\hline & Min & $(0.933)$ & $(3.655)$ \\
\hline \multirow[t]{3}{*}{ Energy } & Mean & 2.634 & 2.457 \\
\hline & $\operatorname{Max}$ & 5.155 & 5.797 \\
\hline & Min & 0.214 & $(0.428)$ \\
\hline \multirow[t]{3}{*}{ Construction } & Mean & 1.505 & 3.393 \\
\hline & $\operatorname{Max}$ & 3.648 & 8.805 \\
\hline & Min & 0.642 & 1.127 \\
\hline \multicolumn{4}{|c|}{2011} \\
\hline & & $Z^{\prime}$ & $\mathrm{Z}^{\prime \prime}$ \\
\hline \multirow[t]{3}{*}{ Telecommunication $^{1}$} & Mean & 1.361 & 1.983 \\
\hline & Max & 3.541 & 7.301 \\
\hline & Min & $(1.005)$ & $(3.190)$ \\
\hline \multirow[t]{3}{*}{ Energy } & Mean & 4.073 & 4.012 \\
\hline & $\operatorname{Max}$ & 7.038 & 8.773 \\
\hline & Min & 1.471 & 1.782 \\
\hline \multirow[t]{3}{*}{ Construction } & Mean & 1.880 & 3.739 \\
\hline & Max & 4.995 & 11.209 \\
\hline & Min & 0.705 & 1.057 \\
\hline
\end{tabular}

Source: Authors' estimations.

According to Figure 1, not much may be analyzed regarding the financial distress position of the telecommunication company, referring to the Z' score.

\footnotetext{
${ }^{1}$ One of the five companies, which are part of the telecommunication sector sample, has no public data available for 2011. This company is not part of the $\mathrm{Z}$ score and financial ratio sector assessment for 2011.
} 
All results of the model with five independent variables are within the gray area, independently from the year under consideration. The last two years, according to the $Z^{\prime \prime}$ score, seem to have brought the telecommunication sector far away from insolvency problems.

Figure 1. Telecommunication Score

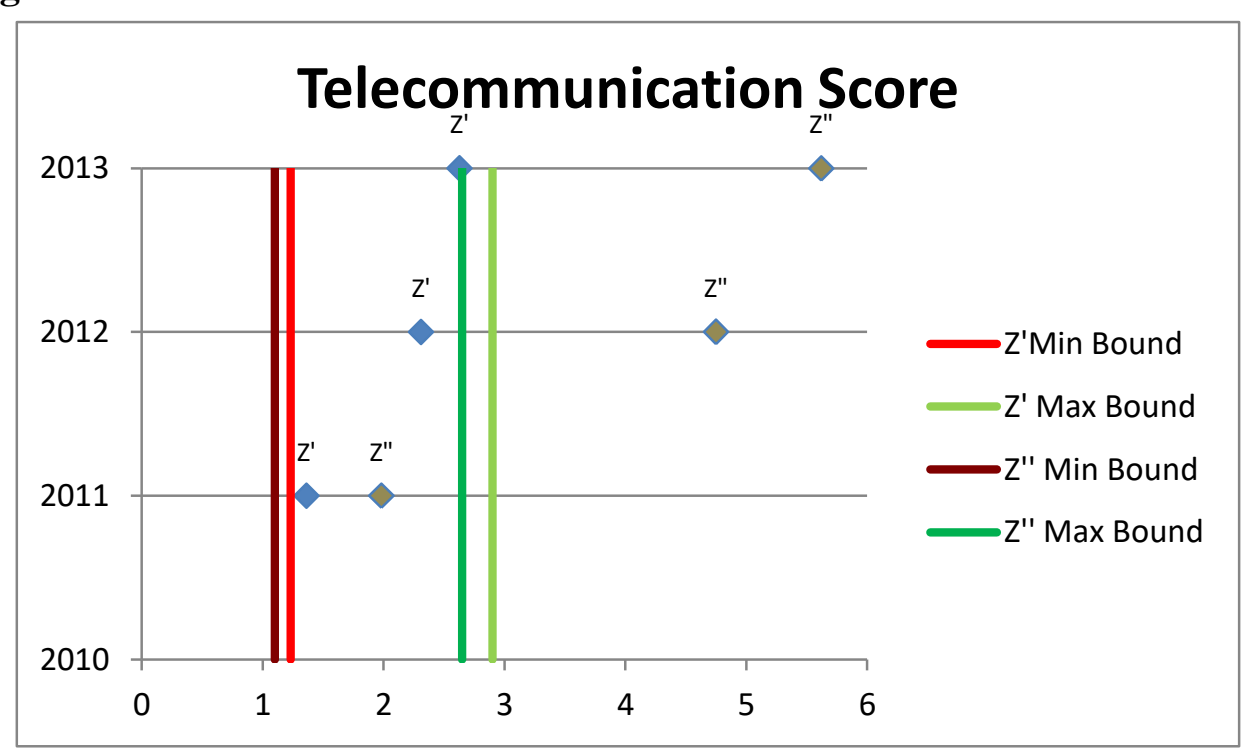

Source: Authors' estimations.

The construction sector, according to Figure 2, provides mixed information from the two models. $Z^{\prime}$ classified the construction sector within the gray area, while $Z^{\prime \prime}$ classified the sector as solvent, independently from the years under consideration. The distance with the gray area has been diminishing from year to year, however.

Figure 2. Construction Score

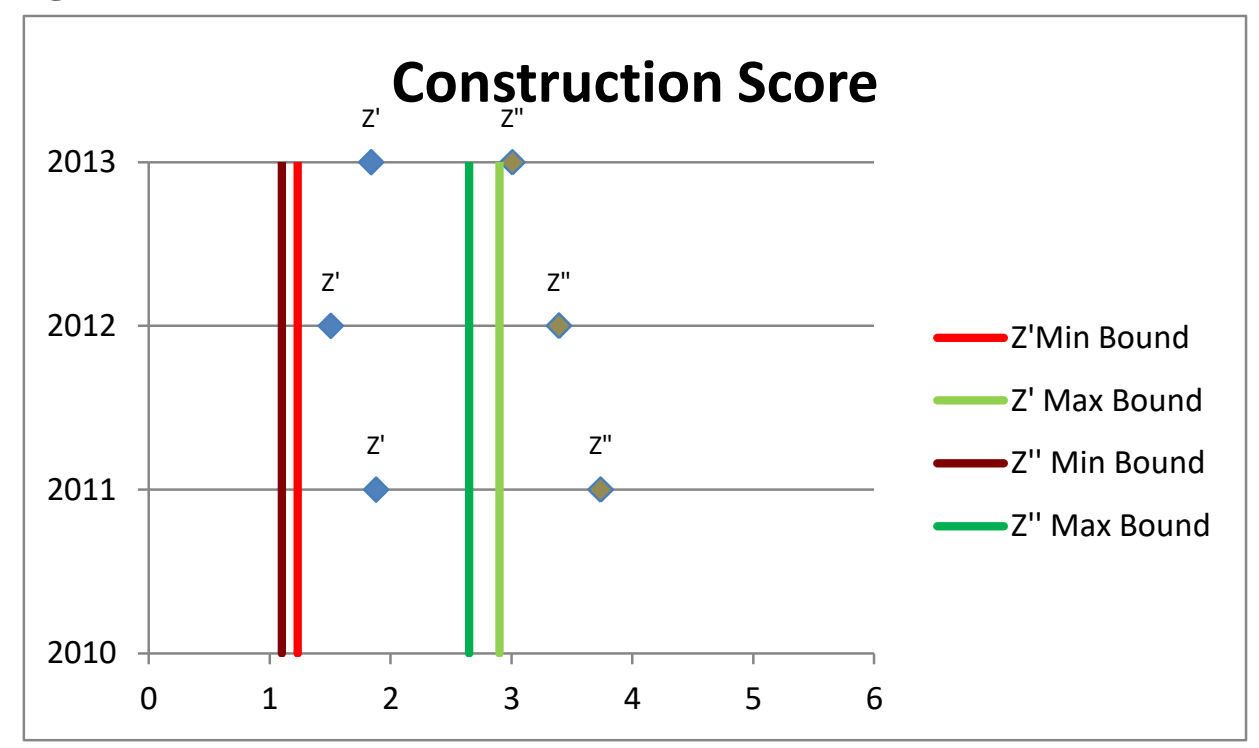

Source: Authors' estimations. 
Figure 3 shows that, independently from the models used, only in 2011 the energy sector has not been exposed to any distress. The $Z^{\prime}$ and $Z^{\prime \prime}$ results could not say much about the solvency position of the sector during the last two years of study.

Figure 3. Energy Score

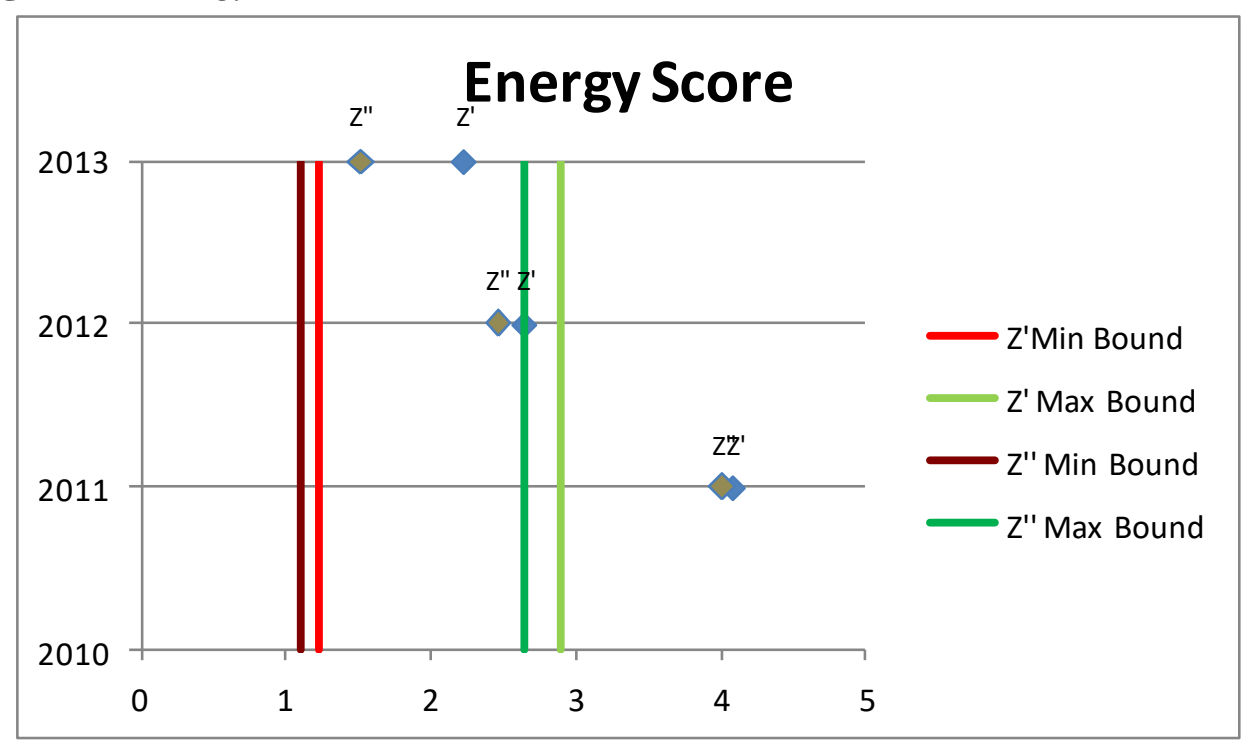

Source: Authors' estimations.

This section showed that the highest score is achieved from the telecommunication sector in 2013, independently from the model used. The energy sector seemed to be more exposed to financial distress from year to year, while the construction sector, as per the Z" model, showed no distress, independently from the considered year. All sectors considered in this research could not be explicitly considered as bankrupt, independently from the year and models used, during the period under examination.

The next section analytically investigates the causes of distress performance differentials through the financial ratio analysis.

\section{Investigation of Distress Performance through Ratio Analysis}

Considering the results in Table 2, while the mean of Working Capital/Total Assets has increased through the years of study for the telecommunication, the variability has increased as well. The same is valid for the Equity Book Value/Total Liability score. Both ratios have shown the highest impact in solvency, as per the Z" model. While the EBIT/Total Assets ratio, with the increase of the mean and the decrease of variability, showed the most desired trend for the telecommunication sector through the years, cumulative profitability over time shows negative signal for the telecommunication sector, especially in the last year studied. 
The net liquid asset measure as a fraction of total capitalization, and sale generating ability of the assets of the telecommunication sector, showed no advantage as compared with the other two sectors considered in this research. However the latter affects the $\mathrm{Z}^{\prime}$ score only. While showing comparative advantage in terms of the cumulative profitability, asset productivity, and leverage towards the energy sector for the last two years, telecommunication companies seem to be more financially distressed in terms of cumulative profitability and asset productivity, compared to the construction companies operating in Albania. Both ratios for the construction companies were almost twice the telecommunication companies' ratios.

The energy sector has shown a decrease of the net liquidity, cumulative profitability, asset productivity and leverage from 2012 to 2013, while increasing the variation of all these ratios. The same explanation applies for the first three measures from 2011 to 2012. Sales generating the ability of a company's assets, although showing a decreasing trend for the energy sector, have decreased in variability within the sector as well. All the ratios, however, have shown deterioration during the period of 2011-2013, and, for this reason, both the $\mathrm{Z}$ models considered in this study show a higher financial distress for the energy sector with time passing.

With the competitive position towards the telecommunication sector considered above, based on the data of Table 2, we may say that the energy sector has had a better leverage position and sales generating ability of assets towards the construction sector, independently from the year under consideration.

The construction sector was characterized by an increasing variability of all ratios from year to year. While in 2013, except the liquidity net position, all other ratios show improvement, the previous year financial data showed the contrary. Since net liquidity position is highly weighted by the $Z^{\prime \prime}$ model, the score decreases from 2012 to 2013. 
Table 2. Summary Statistics of the Financial Ratios of the Industries Included in this Study

\begin{tabular}{|c|c|c|c|c|c|c|}
\hline \multicolumn{7}{|c|}{2013} \\
\hline & & WC/TA (X1) & RET.EAR/TA (X2) & EBIT/TA (X3) & EQ BV/TL (X4) & SALES/TA (X5) \\
\hline \multirow[t]{3}{*}{ Telecommunication } & Mean & 0.050 & 0.082 & 0.043 & 4.508 & 0.496 \\
\hline & Max & 0.612 & 0.628 & 0.132 & 13.331 & 0.807 \\
\hline & Min & $(0.251)$ & $(0.972)$ & $(0.164)$ & $(0.030)$ & 0.158 \\
\hline \multirow[t]{3}{*}{ Energy } & Mean & 0.105 & $(0.110)$ & $(0.044)$ & 1.415 & 1.780 \\
\hline & Max & 0.296 & 0.094 & 0.093 & 4.952 & 3.677 \\
\hline & Min & $(0.417)$ & $(0.682)$ & $(0.409)$ & 0.205 & 0.058 \\
\hline \multirow[t]{3}{*}{ Construction } & Mean & 0.152 & 0.197 & 0.078 & 0.804 & 0.985 \\
\hline & Max & 0.398 & 0.768 & 0.225 & 3.187 & 2.825 \\
\hline & Min & $(0.030)$ & 0.005 & 0.006 & 0.006 & 0.242 \\
\hline \multicolumn{7}{|c|}{2012} \\
\hline & & WC/TA (X1) & RET.EAR/TA (X2) & EBIT/TA (X3) & EQ BV/TL (X4) & SALES/TA (X5) \\
\hline \multirow{3}{*}{ Telecommunication } & Mean & 0.035 & 0.116 & 0.025 & 3.784 & 0.519 \\
\hline & Max & 0.445 & 0.585 & 0.204 & 11.965 & 0.892 \\
\hline & Min & $(0.234)$ & $(0.661)$ & $(0.220)$ & 0.142 & 0.170 \\
\hline \multirow[t]{3}{*}{ Energy } & Mean & 0.141 & $(0.029)$ & $(0.005)$ & 1.580 & 1.912 \\
\hline & Max & 0.302 & 0.082 & 0.058 & 4.439 & 4.490 \\
\hline & Min & $(0.158)$ & $(0.158)$ & $(0.117)$ & 0.409 & 0.062 \\
\hline \multirow[t]{3}{*}{ Construction } & Mean & 0.264 & 0.166 & 0.061 & 0.677 & 0.702 \\
\hline & Max & 0.585 & 0.739 & 0.210 & 2.711 & 1.410 \\
\hline & Min & 0.119 & 0.005 & 0.003 & 0.006 & 0.238 \\
\hline
\end{tabular}




\begin{tabular}{|c|c|c|c|c|c|c|}
\hline \multicolumn{7}{|c|}{2011} \\
\hline & & WC/TA (X1) & RET.EAR/TA (X2) & EBIT/TA (X3) & EQ BV/TL (X4) & SALES/TA (X5) \\
\hline \multirow[t]{3}{*}{ Telecommunication $^{1}$} & Mean & $(0.013)$ & 0.038 & $(0.019)$ & 1.969 & 0.571 \\
\hline & Max & 0.093 & 0.545 & 0.194 & 3.973 & 0.963 \\
\hline & Min & $(0.096)$ & $(0.395)$ & $(0.291)$ & 0.086 & 0.108 \\
\hline \multirow[t]{3}{*}{ Energy } & Mean & 0.188 & $(0.002)$ & 0.048 & 2.343 & 2.812 \\
\hline & $\operatorname{Max}$ & 0.352 & 0.069 & 0.124 & 6.774 & 6.161 \\
\hline & Min & 0.001 & $(0.128)$ & $(0.012)$ & 0.204 & 0.124 \\
\hline \multirow[t]{3}{*}{ Construction } & Mean & 0.243 & 0.172 & 0.095 & 0.894 & 0.889 \\
\hline & Max & 0.510 & 0.798 & 0.328 & 3.710 & 1.471 \\
\hline & Min & 0.056 & 0.007 & 0.021 & 0.008 & 0.373 \\
\hline
\end{tabular}

Source: Authors' estimations.

\footnotetext{
${ }^{1}$ One of the five companies, which are part of the telecommunication sector sample, has no public data available for 2011 . This company is not part of the Z score and financial ratio sector assessment for 2011.
} 
This section summarizes specific ratio analysis and its effect to the financial distress position of the sectors considered in this study. The net liquidity and leverage position improve from year to year for the telecommunication companies, while being more exposed to distress in terms of cumulative profitability and productivity, as compared with the construction sector. The energy sector has shown a decrease in all ratios throughout the years, resulting in an increasing exposure to financial distress, considering both models used in this research. The construction companies have shown an increasing variability of ratios throughout the years. Next section presents the concluding remarks of this study.

\section{Concluding Remarks}

This research studies the financial distress characteristics of the telecommunication, construction and energy sector operating in Albania. Due to the impossibility of the market characteristics cited in this work, the original Z score model and the Emerging Market Models, proposed by Altman $(1968,2005)$, have not been used in this research. We used the modified version of the original $\mathrm{Z}$ model, $\mathrm{Z}^{\prime}$ and $\mathrm{Z}^{\prime \prime}$, as proposed by Altman and Heine (2000), for the financial distress analysis of the business sector. We selected five companies in each sector from the VIP list of the Albanian Tax Authority. We find financial data for the period 2011-2013.

The lowest exposure to financial distress, for 2013, is shown from the telecommunication sector. The increasing risk of bankruptcy, throughout the years, seemed to characterize the energy sector, while construction, according to the $\mathrm{Z}^{\prime \prime}$ model, is the least exposed sector toward financial problems throughout the years. In no case, a specific sector may be considered as default, based on this study.

The liquidity and leverage position seem to have improved for the telecommunication companies throughout the years, although exposure towards financial problems seem to be higher than the construction sector, when considering cumulative profitability and productivity. The energy sector showed an increasing trend, through all ratios, toward potential bankruptcy. The construction sector seems to have been exposed to higher variability of ratios, throughout the years.

One of the extensions of this study is the quantitative assessment of local financial data with the goal of achieving a characteristic $\mathrm{Z}$ model for the Albanian market, as suggested by Altman (2005) and Muminovic (2013). The limitation, however, is the difficulty in finding bankruptcy cases and respective financial information to properly quantify and test loadings. Another extension may be the consideration of more companies in the sample of the three sectors considered in this study. 


\section{References}

Altman E (1968) Financial ratios, discriminant analysis and the prediction of corporate bankruptcy. The Journal of Finance 23(4/Sep.): 589-609.

Altman E (2005) An emerging market credit scoring system for corporate bonds. Emerging Markets Review 6(4): 311-323.

Altman IE, Danovi A, Falini A (2013) Z-Score models' application to Italian companies subject to extraordinary administration. Journal of Applied Finance 23(1): 128-137.

Altman E, Haldeman R, Narayanan P (1977) Zeta Analysis: A new model to identify bankruptcy risk of corporations. Journal of Banking and Finance 1(1/Jan.): $29-54$.

Altman E, Heine M (2000) Predicting financial distress of companies: Revisiting the Z Score and Zeta Models. Handbook of Research Methods and Applications in Empirical Finance 09/2000. DOI: 10.4337/9780857936097. 00027.

Altman IE, Iwanicz-Drozdowska M, Laitinen KE, Suvas A (2014) Distressed Firm and Bankruptcy Prediction in an International Context: A Review and Empirical Analysis of Altman's Z-Score Model. Working Paper (August 10, 2014).

Anjum S (2012) Business bankruptcy prediction models: A significant study of the Altman's Z score model. Asian Journal of Management Research 3(1): 212219.

Balcaen S, Ooghe H (2004) 35 Years of Studies on Business Failure: An Overview of the Classical Statistical Methodologies and their Related Problems. Working Paper. (Jan. 2004).

Beaver W (1966) Financial Ratios as Predictors of Failure. Journal of Accounting Research 4: 71-111.

Chava S, Jarrow AR (2004) Bankruptcy prediction with industry effects. Review of Finance 8(4): 537-569.

Hayes S, Hodge K, Hughes L (2010) A study of the efficacy of Altman's Z to predict bankruptcy of specialty retail firms doing business in contemporary times. Economic and Business Journal: Inquiries and Perspectives 3(1/Oct.): $122-134$.

Muminovic S (2013) Revaluation and Altman's Z score - the case of the Serbian capital market. International Journal of Finance and Accounting 2(1): 13-18.

Smith M, Liou D-K (2007) Industrial sector and financial distress. Managerial Auditing Journal 22(4/Apr.): 376-391. 
